\title{
Science diplomacy: new day or false dawn?
} Lloyd Davis; Robert Patman

Singapore: World Scientific Publishing Company, 2015, 296 p.

ISBN: 978-981-4440-06-6

Danilo Reis*

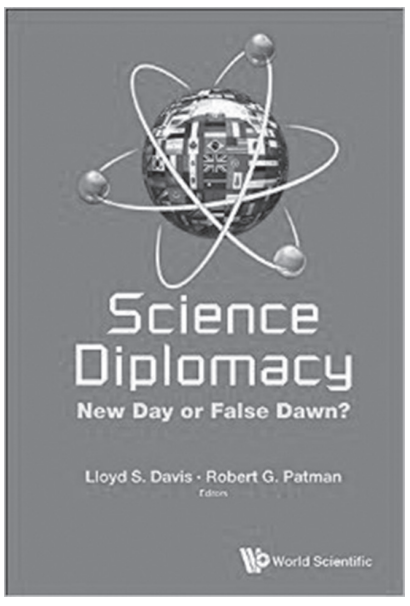

A implementação de projetos de cooperação internacional em ciência, tecnologia e inovação tem sido ampliada desde o fim da Segunda Guerra. Em estudos sobre relações internacionais, fenômenos dessa natureza são tradicionalmente analisados no âmbito da Cooperação Internacional para o Desenvolvimento (CID), especialmente sob a designação de Cooperação Técnica (CT). Nesse sentido, a colaboração científica entre atores internacionais é investigada sob a ótica da relevância desses projetos para o aprimoramento econômico e a consequente melhoria do bem-estar social das sociedades envolvidas.

Entretanto, especialmente ao longo da última década, outras dimensões têm sido utilizadas nos estudos internacionais, objetivando investigar apropriadamente projetos de cooperação tecnológica. Em grande medida, tais estudos intentam acompanhar as transformaçôes ocorridas nesse processo cooperativo desde a implantação do Plano Marshall, marco histórico usualmente concebido como institucionalização da CID. Essa mudança analítica é a estrutura fundamental da obra Science diplomacy: new day or false dawn?, editada por Lloyd Davis e Robert Patman, professores da Universidade de Otago, na Nova Zelândia.

\footnotetext{
* Universidade Estadual da Paraíba (UEPB), João Pessoa (PB), Brasil. Email: daniloreisri@gmail.com
} 
Os modismos intelectuais têm se mostrado continuamente presentes no âmbito da academia. Nesse sentido, a preocupação principal de Davis e Portman, ao reunirem nesse volume uma série de contribuições sobre as soluções que a ciência e a tecnologia podem oferecer para o enfrentamento das problemáticas contemporâneas, mostra-se evidente no título da obra. Podem-se destacar as seguintes questôes principais que permeiam os 14 capítulos do volume: existe uma diplomacia científica per se entre os variados atores internacionais? Caso exista, quais são os seus objetivos principais e a pertinência para os desafios enfrentados, hodiernamente, pela humanidade? Por fim, como estudá-la de um ponto de vista científico?

De acordo com os textos escolhidos para compor o volume, a primeira questão deve ser respondida afirmativamente. Desse modo, apreende-se da leitura da obra que há um fenômeno internacional chamado de diplomacia científica, um objeto de análise independente da CT, que pode ser definido como "o processo pelo qual os Estados se fazem representar e pelo qual defendem seus interesses no cenário internacional nas áreas relacionadas à aquisição, utilização e comunicação do conhecimento adquirido pelo método científico" (DAVIS; PATMAN, 2015, p. 23, tradução nossa).

Com a finalidade de responder aos demais questionamentos expostos, Davis e Patman estruturaram o volume em três partes a partir das reflexões e terminologias apresentadas pelo estudo New frontiers in science diplomacy: navigating the changing balance of power, trabalho seminal realizado pela Royal Society de Londres e pela American Association for the Advancement of Science (AAAS). ${ }^{1}$ De acordo com esse estudo, pode-se considerar a diplomacia científica sob três dimensões basilares: a diplomacia pela ciência; a ciência na diplomacia; e a ciência pela diplomacia (THE ROYAL SOCIETY, 2010, p. vi).

A dimensão da diplomacia pela ciência é definida pela Royal Society (2010, p. vi) como o desenvolvimento de processos que se dedicam "a facilitar a cooperação científica internacional”. Ou seja, por meio da atuação das políticas externas dos diferentes Estados, são implementados projetos científicos comuns. A primeira parte da obra apresenta quatro ensaios sob essa perspectiva.

Nesse sentido, Cathleen Campbell analisa a relevância da cooperação científica no discurso realizado por Barack Obama no Cairo, em junho de 2009. Conforme a autora, por se tratar de uma área imparcial e na qual a liderança norte-americana é percebida de forma positiva pelos Estados árabes, uma maior aproximação di-

1 Desde 2013, essa organização edita um periódico dedicado exclusivamente aos estudos sobre diplomacia científica. Para mais detalhes sobre a publicação e aquisição gratuita dos seus volumes, acessar: <http://www.sciencediplomacy.org/>. 
plomática entre esses países e os Estados Unidos poderia ocorrer caso a finalidade dessa harmonização fosse o desenvolvimento de projetos científicos em conjunto. Ademais, outro exemplo de diplomacia pela ciência presente na obra consiste no projeto Square Kilometre Array (SKA), desenvolvido conjuntamente entre Austrália e África do Sul. O SKA, iniciado nos anos 1990, objetiva a construção do maior telescópio do mundo até 2017.

Historicamente, diplomatas, estadistas e funcionários públicos em geral têm utilizado o conhecimento de cientistas das mais diversas áreas com o intuito de defender os interesses nacionais das suas respectivas nações e, por conseguinte, aprimorar o debate internacional em questôes como meio ambiente, segurança, saúde, etc. A segunda parte do volume editado pelos professores da Universidade de Otago apresenta quatro ensaios sobre essa temática, ou seja, sobre a ciência na diplomacia.

Nesse sentido, analisa-se o papel da comunidade científica em problemáticas como mudança climática e aquecimento global, além da utilização das novas tecnologias da comunicação no contexto internacional. Em relação a esse tema, Daryl Copeland, por exemplo, analisa o impacto da divulgação de documentos confidenciais perpetrada pelo Wikileaks e as possíveis consequências que esses acontecimentos podem acarretar nas relações exteriores dos Estados envolvidos. $\mathrm{O}$ autor conclui que os governos precisam coordenar suas respectivas açôes em diplomacia tecnológica a partir de um acompanhamento contínuo da comunidade científica, implementando um plano estratégico comum que harmonize as burocracias estatais e as suas necessidades nos planos doméstico e internacional.

Finalmente, a terceira parte do volume é dedicada à ciência pela diplomacia. De acordo com a Royal Society (2010, p. vi), essa dimensão pode ser definida como "a utilização da cooperação científica com o objetivo de aprimorar as relações entre os países". Assim, analisam-se projetos que envolvem ciência e tecnologia nas áreas de segurança, saúde e comércio. Destaca-se a relevância que a ciência pela diplomacia tem adquirido no Japão, onde é possível argumentar que projetos em tecnologia desenvolvidos em parceria com a Coreia do Sul têm ajudado a reduzir a histórica rivalidade entre essas duas naçôes.

Em suma, a obra é uma importante contribuição entre os incipientes estudos contemporâneos que investigam diplomacia e ciência, auxiliando a responder de maneira positiva ao questionamento apresentado no seu subtítulo. Assim, Davis e Patman (2015, p. 270, tradução nossa) concluem que, apesar das suas limitações, deve-se "eliminar a noção de que a diplomacia científica seria um falso amanhecer". 


\section{Referências bibliográficas}

DAVIS, Lloyd; PATMAN, Robert. Science diplomacy: new day or false dawn? Singapore: World Scientific, 2015.

THE ROYAL SOCIETY. New frontiers in science diplomacy: navigating the changing balance of power. 2010. Disponível em: <https://royalsociety.org/ /media/Royal_Society_Content/ policy/publications/2010/4294969468.pdf>. Acesso em: 23 maio 2015. 